\title{
THE EMERGENCE OF LOGISTICS CITIES: CONCEPTUAL MODEL
}

\author{
C. SENGPIEHL \\ R. OAKDEN \\ P. NAGEL \\ K.T.K. TOH \\ P. SHI \\ carsten.sengpiehl@vu.edu.au \\ Institute for Logistics and Supply Chain Management, \\ Victoria University, Melbourne, Australia
}

\begin{abstract}
This paper describes the emergence of logistics cities, which are geographical concentrations of related industries situated around one or more international trade gateways adjacent to a metropolitan area. Broadly, a logistics city comprises logistics activities and related assets combined with an integrated mix of manufacturing and assembly companies, business services, retail outlets, research and education centres, and associated government services and administration sections. This concept is currently being promoted and developed globally by several regions, and examples of these logistics cities are described in this paper. Drawing from these examples and the limited available literature, a preliminary conceptual map of the logistics cities concept has been developed which incorporates a theoretical foundation of economic development and the principles of competitiveness in the notion of trade clusters. This map has provided the basis for our further investigations and the continued development of a more detailed conceptual model that will provide a systematic knowledge base for those engaged in the development of further logistics cities. The beneficiaries of this model will be public authorities, property developers and industrial concerns, and will be used when making decisions for future logistics infrastructure, services, supporting services and related social elements.
\end{abstract}

\section{INTRODUCTION}

Trade competition between regions and countries has increased significantly in recent years, partly due to developments in globalisation and advances in technology. As a consequence, the strategic planning of a region to take advantage of its position in the context of its connectivity function between key economic centres will play an important role in the sustainable future of the region. In supporting industry and commerce within a region, relevant governments will encourage regional investment and will work to align laws and regulations across boundaries to free up global trade and transportation. This input is 
essential, because the global connectivity of a metropolitan area and its ability to retain and further develop its "competitive advantage", requires a significant review of the way in which the country interfaces physically, virtually and legally with the rest of the world. In addition, an overarching strategy is required that addresses a well-structured and relevant solution to the longer-term sustainability of a region's economy in the global trading arena. We believe that the concept of a logistics city can be seen as a major part of this strategy.

The Institute for Logistics and Supply Chain Management at Victoria University (ILSCM 2007c) is currently focusing its research on this concept of a logistics city and has defined it as the final progression of a dense trade cluster. Dense trade clusters are described as nodal points, which can be positioned away from traditional land, air and coastal borders that enable international trade. The facilitation of trade is accomplished by strategic investment in logistics-related infrastructure such as multimodal transport facilities and by promoting value-added services (ILSCM, 2007b; Cambridge Systematics Inc., 2004).

The concept of a logistics city broadly represents a geographical metropolitan area with its main function being a logistical platform providing appropriate logistics infrastructure and physical facilities (roads, rail tracks, terminals and IT infrastructure) and substantial existing logistical services (warehousing, distribution and freight forwarding). However, in addition there are a range of related business value-added services (such as legal, finance and light assembly factories) and social infrastructure components (including education, health and recreation facilities) that are necessary elements for the logistics city to act as an integrated concept.

In their study of intermodal freight literature, Bontekoning et al. (2004) state that, as is typical for a research field in the pre-paradigmatic phase, there is a lack of a consensus definition and a common conceptual model. This is currently true for the wider logistics city concept and therefore this paper provides an initial conceptual model, through the development and description of the logistics city a mind-map.

At present, the ILSCM (2007c) investigation has identified three main key "enablers" for the development of logistics cities. The consolidation of the geographic dispersion is the first enabler, which highlights logistics sites as focal points for services connecting industry to the main logistics hubs. However, our current understandings of this enabler relate to the historically grown areas and might not apply in green field logistics cities. Value-added services, apart from logistics operations, are a key component in the development of logistics cities. Therefore the second main enabler is called "enhanced professional and business services". The third enabler, "increased transport infrastructure capacity", is related to the enhancement of capacity and connectivity between logistics sites, residential and business/ industrial centres through the application of intelligent transport system technology. 
So far there has been little scientific discussion about the key elements of logistics cities in terms of their structure and composition, the services which they provide and their hierarchical relationships and logical interconnections. However, it is evident that industry has embraced this concept without too much academic consideration, as identified in the initial interviews.

Recent research by the ILSCM (2007a) proposes four designations of dense trade clusters, namely freight villages, inland ports, logistics hubs and logistics cities, which progress in order of size and range of services provided. The logistics city is seen as the largest designation within a dense trade cluster, making the other three designations subsets of a logistics city.

Our review of the literature which focused on the definition, specification, characteristics and services of a logistics city, has shown a number of contradictory designations. It appears that the characteristics, elements of logistics centres and freight villages are very similar and that logistics centres have no unanimously agreed name. It was concluded that freight villages and logistics centres are synonymous (Meidute, 2005; Europlatforms EEIG, 2004).

There are also several studies and publications describing logistics centres and freight villages (Meidute, 2005; Tsamboulas, 2005; Europlatforms EEIG, 2004; Breitzmann and Wenske, 2003) which have highlighted definitions of freight villages, their specific services, characteristics and elements. Tsamboulas and Dimitropoulos (1999) made a significant statement in saying that intermodal terminals constitute the principal component of freight villages, and further suggested that freight villages are more than just a terminal as they provide additional facilities and services.

An important (but limited) consideration by Meidute (2005) is their two-fold approach to logistics centres. The first approach is that logistics centres are part of a transportation infrastructure which is designed to conduct transportation activities, and secondly that logistics centres are a generator of business to stimulate international trade and regional economic growth.

Ballis (2006) expressed a unique opinion that the term "inland port" is a synonym of freight villages. The ILSCM (2007a), on the other hand, distinguished between freight villages and inland ports by stating that an inland port has the "bill of lading" as the final destination, unlike freight villages. These differing uses of the common elements of logistics cities have led to the authors' attempt to develop an unambiguous model that facilitates design and communication.

Based on field interviews and focus group discussions, Walter and Poist (2003) identified 12 characteristics and services of an inland port, and additionally measured the importance and 
perception of shippers and carriers regarding these services and characteristics. Another study by Leitner and Harrison (2001) included a detailed trade analysis and the identification of inland ports as well as their impact in terms of trade and transportation. In both studies, the definition of an inland port is similar and both assume that the transport assets are in general multimodal and the trade is processed by value-added services. Leitner and Harrison (2001) additionally identified several other variants of this port activity, listing the inland waterway port, the air cargo port, the maritime feeder inland port, and the trade and transportation centre inland port as the four classes of inland ports. The IBI Group (2006) however, has classified inland ports by three specific methods, using as the modal orientation, the distance from a maritime port and the principal traffic as distinguishing criteria.

Closer examination of the definitions, services and characteristics of freight villages and inland ports indicates a small disparity, however, which has a major impact. Foreign trade zones, including light assembly and bonded warehouse services for tariff and tax postponement reasons, are only mentioned in conjunction with inland ports; hence, the statement by Ballis (2006) that inland port is a synonym of freight village, based on the literature review, is vague and the ILSCM's (2007a) definition has been offered as a more precise alternative.

The fact that Tsamboulas and Dimitropoulos (1999) stated that intermodal terminals are the principal component of freight villages and that the transport assets of inland ports are in general multimodal, led to an additional investigation for intermodal freight terminals. McCalla et al. (2001) described intermodal freight terminals as the point of transfer of freight from one transport mode to another, which requires a large amount of land with a high degree of accessibility. In a later study, Sirikijpanichkul and Ferreira (2005) identified three criteria to classify intermodal freight terminals, naming them connector, size and organisation. Aifandopoulou et al. (2006), on the other hand, defined four special classes, based on a survey of south-east Europe. These recognised types are city terminals, freight villages, industrial/logistic parks and special logistics areas. Clearly, this effort of classification can be seen as a controversial subject, due to the fact that Tsamboulas and Dimitropoulos (1999) interpret the terminal as an element of freight villages rather then seeing the freight villages as a class of intermodal freight terminals, as proposed by Aifandopoulou et al. (2006).

In addition to the mentioned initial investigation, four so-called logistics cities, being planned and developed or in an expansion phase, are found in the literature. They are:

- Dubai (Proffitt, 2006; MEED, 2006; Turner, 2006)

- Lingang, which is adjacent to Shanghai in China (Leach, 2006; Lingang Group, 2006)

- Zaragoza in Spain (Tierney, 2004)

- Shenzhen in China (Shenzhen Government Online, 2007; China Economic Review, 2007; Hong Kong Trade Development Council, 2004; Jun, 2004).

These logistics cities differ in size, and focus on different elements, infrastructures and services provided. For example the logistics city in Dubai is seen as the logistics area of the 
comprehensive structure of Dubai World Central. In contrast, the logistics cities of Lingang and Shenzhen include all other elements of Dubai World Central and are clearly referred to as logistics cities in publication materials. In addition, Zaragoza, located inland, appears small in comparison to Dubai and Lingang.

However, all these centres have commonalities. They include or are adjacent to ports that include seaports, airports and inland ports. All of them provide sufficient transport and communication infrastructure, logistics parks and facilities as well as related logistics services, although admittedly these differ in size and the nature of services provided. Value-added business services such as light assembly, banking and hospitality are integrated in these logistics cities; hence the value services as an enabler, mentioned by ILSCM (2007c), can be seen as a necessity for the development of logistics cities. Additionally the free trade zones and research/education facilities seem to be an important part of the logistics city concept. Finally, all of the identified logistics cities are part of an economic development plan of their related regional government.

The first conclusion that we can make from our review of publications is that there are many different perspectives on the proposed elements of a logistics city, and the elements or designations have emerged as contradictory and overlapping. Additionally, there is an absence of an academically justified conceptual model to adequately or clearly identify the distinct physical characteristics, operations, valued-added business services and social components of a logistics city.

The second conclusion that arose from the investigation is that the emergent logistics city concept and indeed the name itself is used very freely and is accepted by industry as a viable and unique concept. Metropolitan areas, such as Hamburg (harbour city), Singapore (logistics cluster) and Rotterdam (port city), with their long seaport and trade history, include massive transport infrastructure, logistics activities and value-added business services, and are seen as a logistics city concept by various authors even though they are not named as such. Van der Lugt and de Langen (2005) support this conclusion by describing the changing role of seaports as locations for logistics activities. As a consequence, we have found that focusing on the concept without relying on the naming convention is more convenient for our investigation.

The third conclusion is that logistics cities are not only found in regions where they are expected such as seaports, but also as dense trade clusters in the less obvious inland locations like Zaragoza, Duisburg and Fort Worth/Dallas. The development and extensions of a logistics city, in particular its "trade gateway" function and its related primary and secondary transport infrastructure, cannot be fully evaluated without relating it to its geographical location and therefore the region in which they are found. The geographical 
location and conditions that are an intimate part of a logistics city play an import role in its essential characteristics and, in an important way, determine the setup, quality and efficiency of its operation. Three important factors in terms of geographical location and conditions appeared: first the geographic accessibility of the logistics city; second the influences on the function of the logistics city due to the geographical location and conditions; and third the pragmatic concerns related to historical dependencies.

\section{DEVELOPMENT OF LOGISTICS CITIES}

The existence of a port, here referred to as an international gateway, that can be either a seaport, airport or inland port, is the most essential element in the logistics city concept. However, it can be argued that there are significant differences between common port cities and logistics cities, and in order to separate common ports from logistics cities, a basic description of various port models is needed to aid the understanding of the differences.

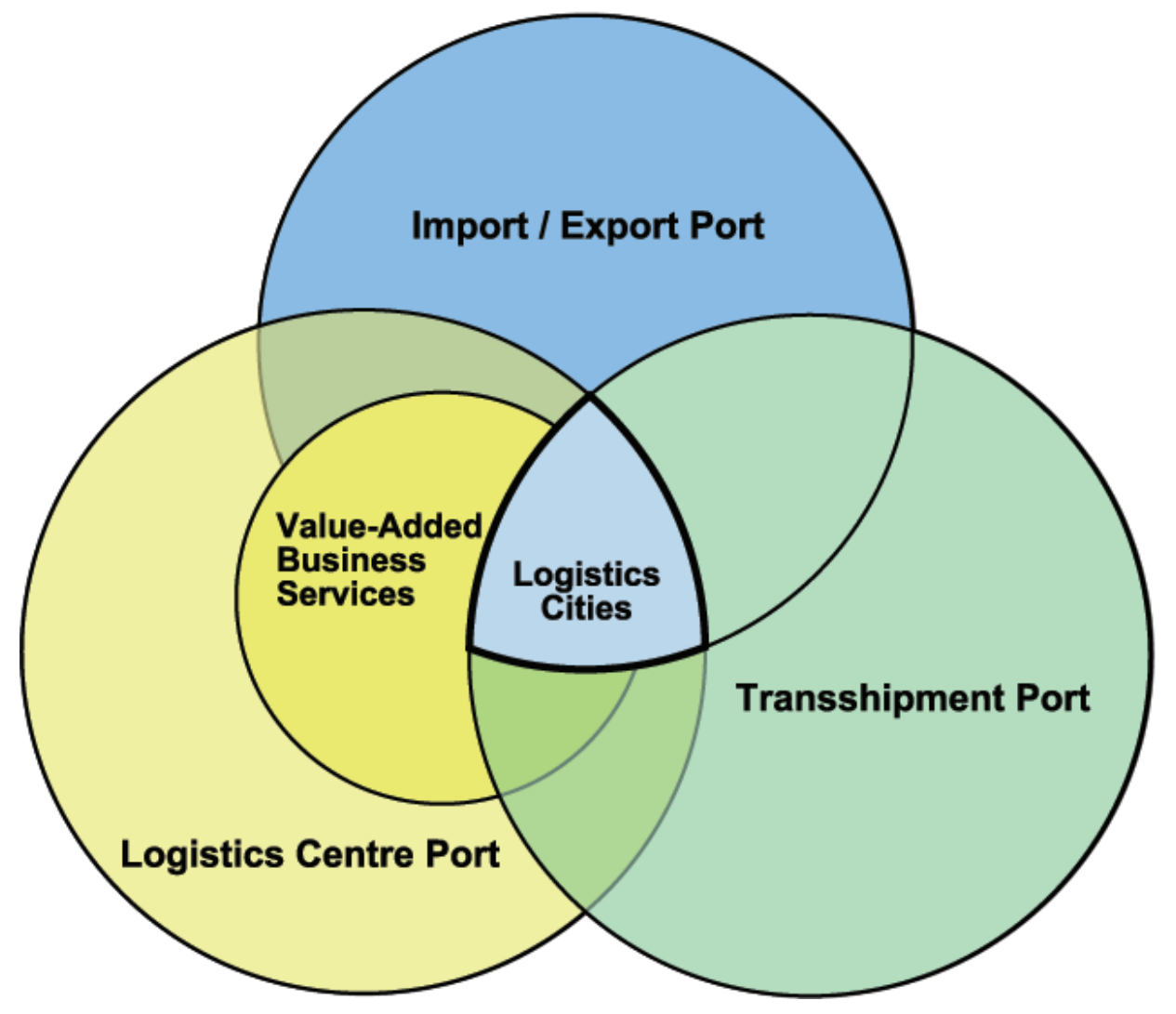

Figure 1: Port model (derived from ESCAP, 2005, p.17)

The regional demand for importing and exporting goods is the nature of the historical port model, which is a traditional import/export port. However, the increased complexity of international trade, in combination with the increased sophisticated demands of port customers and therefore the increased requirements of multinational industries which are passed on to logistics services (Abrahamsson et al., 2003), lead to the inevitable progression 
towards transshipment ports, as part of the hub-and-spoke system, and lastly towards logistics centre ports. The point of intersection of the three port models, which includes value-added business services and social aspects can be seen as generating the logistics city concept.

Market expansion and factor-input as a motive for companies to sell and produce abroad, has a long history. However the liberalisation of trade through the GATT and WTO agreements, free trade zones, the introduction of loading units, the evolution of information and communication technology, and the changes of business practices accelerated the trend towards globalisation. These have had a major impact on logistics management and systems which influenced the evolution of traditional port models towards the dense trade complex concept. The determinants for the emerging logistics city concept can be encapsulated within the following four areas that are briefly described in the next paragraphs:

- trade agreements

- transport technology

- information technology

- changing business practices.

The progress in trade liberalisation through the reduction of trade tariffs and trade barriers due to trade agreements has resulted in increasing world trade. Production, assembly, and quality control activities have been shifted to different regions based on the factor advantage of labour cost or other competitive advantages. This has been a catalyst for companies to focus on logistics management and systems, such as distribution management, location optimisation, inventory management, logistics outsourcing, value-added logistics services and the introduction of supply chain management in the 1980s. Logistics evolved as a distinct factor for companies to achieve competitive advantage.

The emergence of the container as a transport unit in the 1960s was one of the major impacts of transport technology for logistics and trade. They reduced transshipment times in the ports and made transportation of semi-finished or finished goods more economical. In combination with the growing average size of transport vehicles such as deep sea shipping vessels and inland barges, the reduction of operating cost could be achieved through economies of scale and passed on to customers, leading towards more transport and major changes of business practices and logistics systems.

Information and communication technology (ICT) is becoming more integrated in transport and logistics services and its importance is continually rising. Information connectivity has developed towards being a fundamental component for logistics systems and therefore the coordination and integration of information in the multi-company sector. E-commercebased administration and e-commerce services such as handling customs procedure, transmitting and processing of bills of lading and other documents, providing information 
for transport scheduling and links to involved transport companies, tracking and tracing of shipments, quoting and booking, were enabled by the development of ICT. It has increased visibility within the supply chains, which leads to tighter linkage within the system. Through sophisticated ICT, transport operators can evolve into value-added service providers, and major shipping lines can become one-stop freight services providers. Logistics cities like Hamburg use the DAKOSY logistics information system and Rotterdam operates with the INTIS system. However the most sophisticated logistics information systems are provided in Singapore, such as Portnet, TradeNet and Cargo Community Network. The Singapore government, in cooperation with key stakeholders, is developing a trade-integrated information platform (one-stop platform) that will bring together the different systems to enable a seamless information transfer between all parties (ICT Working Group, 2002; MTIWGL, 2002).

The advantage of trade liberalisation and transport and information technology mean business practices change and new production, marketing and logistics business architectures emerge. However, the global market is not homogenous and therefore the adaptation to regional demands has to take place to generate business. Strategies such as production in a few key locations, postponement or delayed configuration and centralised inventory are embedded in today's business world.

Centralised production is underpinned by theories of economies of scale. Standardised modules are shipped close to the end user where customisation and final assembly takes place in distribution centres to meet regional demand and requirements. This allows businesses to take advantage of cost reduction in production while meeting the regional requirements. International companies have, as a result, reduced the number of warehouses and consolidated these into regional distribution centres to reduce total inventory requirements and costs. This move required a reliable information system to allow visible access to changing demands and to reduce reaction times, given longer transport distances inherent in this consolidated approach. Transport and distribution alliances have emerged in combination with the hub-and-spoke approach, which enables shorter transport times and reduces costs due to better transport utilisation.

Abrahamsson et al. (2003) provide a comprehensive description for the evolution of logistics business practice, related to distribution, by presenting three types of logistics based on two long-term case studies. Type one is decentralised logistics that is tightly connected to production or sales. It has as its priority increased internal efficiency, and sees that customer service is related to the geographical distance of the customer, which demands a decentralised responsibility for design and control. The second type is based on centralised logistics and direct distribution that is separated from production and sales. The priorities in this case are reducing the total logistics cost through economies of scale, and hold that 
customer service is related to time and availability of products and services. The third type of emerging logistics system is referred to as being a logistics platform resource base for market development, such as new market positions, marketing strategy and new offers to key customers. Logistics is therefore an integrated part of the company's business model including its manufacturing and sales areas, and is centralised. While the standardisation of processes is necessary to achieve high level results, it is important however to have flexibility to adapt to market segments. These centralised logistics platforms which manage, develop and adapt complete logistics systems in combination with production and sales, are a recently emerging trend.

Van der Lugt and de Langen (2005) analysed the role of seaports in terms of these three logistics concepts, and suggest that seaports can attract the new emerging centralised logistics. Singapore, for example, is growing in this emerging segment to increase diversity and strengthen the competitive position of its port cluster. The recently announced "LondonPlus Development Framework" by the working group of logistics (WGL) in Singapore claims that the highest value return is no longer found in simply moving cargo, but rather in the controlling and optimising of the flow of cargo. The "Plus" aspect is seen as the physical infrastructure to facilitate port handling, the area of ship repair and registry as well as the general logistics and IT activities. The "London" aspect is referred as the "softer" area of transport and distribution - building influential services sectors with highly skilled personnel. The aim of the "London" aspect is to turn Singapore into a platform that has the aim of efficient management of international goods movement as well as a centre for excellence in logistics research and education. In addition, contrary to the statement of Van der Lugt and de Langen (2005) where a port's multinational function will diminish by adopting this concept, this emerging segment in Singapore is seen as an opportunity for a broader hinterland such as China, India, Japan and Australia or even to become the nerve centre managing the logistics limbs (planning and control functions) reaching the whole world.

\section{DEVELOPMENT AND REGIONAL COMPETITIVENESS}

The ILSCM (2007c) states that a logistics city increases the competitiveness of a region and strengthens the regional and economic development. Taking the comments of Meidute (2005) that logistics centres are a generator of business and regional economic growth strengthens the ILSCM (2007c) statement. However, no theoretical evidence in the literature was found that provides an explicit explanation of how and to what extent logistics cities' characteristics and elements strengthen the region. The ILSCM (2007b) proposes that a logistics city is the largest designation of a dense trade cluster, which leads to an excursion into the field of clusters and spatial industrial concentration and their impact on regional development and competitiveness. 
The characteristics for industries to form a specialised concentration were discussed by Marshall in the beginning of the twentieth century. However in the last two decades the interest within economic geography and economics of industrial location has increased (Asheim et al., 2006). Reich (2001), for example, has observed that globalisation and information technology has decreased the importance of specialised concentration. Morgan (2004) and Porter (1998) on the other hand, have shown that newly developed clusters in spatial proximity locations support the development of a region. Economic growth can still benefit from the concentration of specialised industries even as globalisation takes place and efficient information technology becomes available.

There are numerous localised concentrations identified in the literature, such as industrial districts (Paniccia, 2002; Becattini, 1990), new industrial spaces (Scott, 1988), local and regional innovation systems (Asheim and Gertler, 2005) and industrial clusters (Porter, 1998) being the most recognised.

Porter derived the competitiveness of firms into a theory of "the competitiveness of nations" (Porter, 1990). He modelled the effect of location proximity on competitiveness and economic development through four interrelated influences, which are mostly referred as the "Porter diamond". These four influences are:

- factor conditions

- context for firm strategy and rivalry

- demand conditions

- related and supporting industries.

The more developed and intense the interactions of the four influences are, the more competitive the firms, region or nations become. Porter (1998 and 1990) argues that a cluster, a geographical proximate group of interconnected companies and associated institutions in a certain field, will enhance the interactions of the four influences and therefore increases competitiveness and strengthens a region. This theory has become the standard for determining competitiveness and is commonly used as a policy tool. However it has been criticised in terms of cluster definitions and theoretical rigour in the context of competitive advantage (Asheim et al., 2006; Martin and Sunley, 2003).

Asheim and Coenen (2006) and Martin and Sunley (2003) conclude that clusters vary in size as well as type, and cannot be explained by a single formal theory. Therefore it appears that different theories for different clusters are appropriate. Seeing the logistics city as the highest progression of a dense trade cluster or as an agglomeration of logistics facilities, logistics services and value-added services, makes it important to develop a theory for this unique cluster in order to describe its impact on regional competitiveness and development. 


\section{PRELIMINARY CONCEPTUAL MAP OF THE LOGISTICS CITY CONCEPT}

To enable a first common understanding of the logistics city concept, a conceptual map, shown in Figure 2, has been developed. Development of this map was based on initial interviews, the review of publications in terms of the logistics city designations and values, and the literature investigation of the four named logistics cities, as well as the logistics clusters of Singapore and Hamburg. We suggest that this conceptual model will allow the development of a future theory that represents the set of concepts within the logistics city domain and the relationships between those concepts.

As shown in the conceptual model, the logistics city has 'enablers' and 'scopes' with inherent and aggregated relationships that will be briefly explained by providing examples. In addition, while the logistics city concept is referred to as a generator for economic growth, literature and initial interviews have, however, shown that the issue of sustainability has become a very important consideration. Sustainability argues for the balance of economic, social and environmental values. Therefore the overall scope of the concept is to be a sustainable global integrated logistics hub located either inland or on the coast, and this view implies that regional economic growth generated by the logistics city concept means meeting the needs of today without compromising our ability to meet the needs of the future.

Singapore sees their pathway of logistics development as the key for meeting future needs that include the social value aspects such as education and amenities. For the logistics city of Dubai, it is argued that economic growth cannot be achieved without social values. The holistic development in Dubai therefore contains a new residential area, commercial districts and parks that include schools, hospitals, banking and financing, health care centres, religious facilities, police station, libraries, university and research centres. Hamburg, a long established port cluster, focuses on environmental issues, using the notion of sustainability, by arguing that no company or employees would consider locating to or living in a polluted area, which would decrease economic growth. Therefore emission and noise has been reduced by the efforts of government and industry, and new recreation areas have been developed or are under development. Zaragoza is developing a new logistics cluster including a research and education facility. To sustain healthy economic growth, it is asserted that these social and environmental aspects must be considered. Educating future professionals that support the logistics city concept is an import factor in keeping and attracting a highly skilled workforce, as is the ensuring of an appropriate quality of life through development of social and environmental values that help to achieve regional economic growth. 


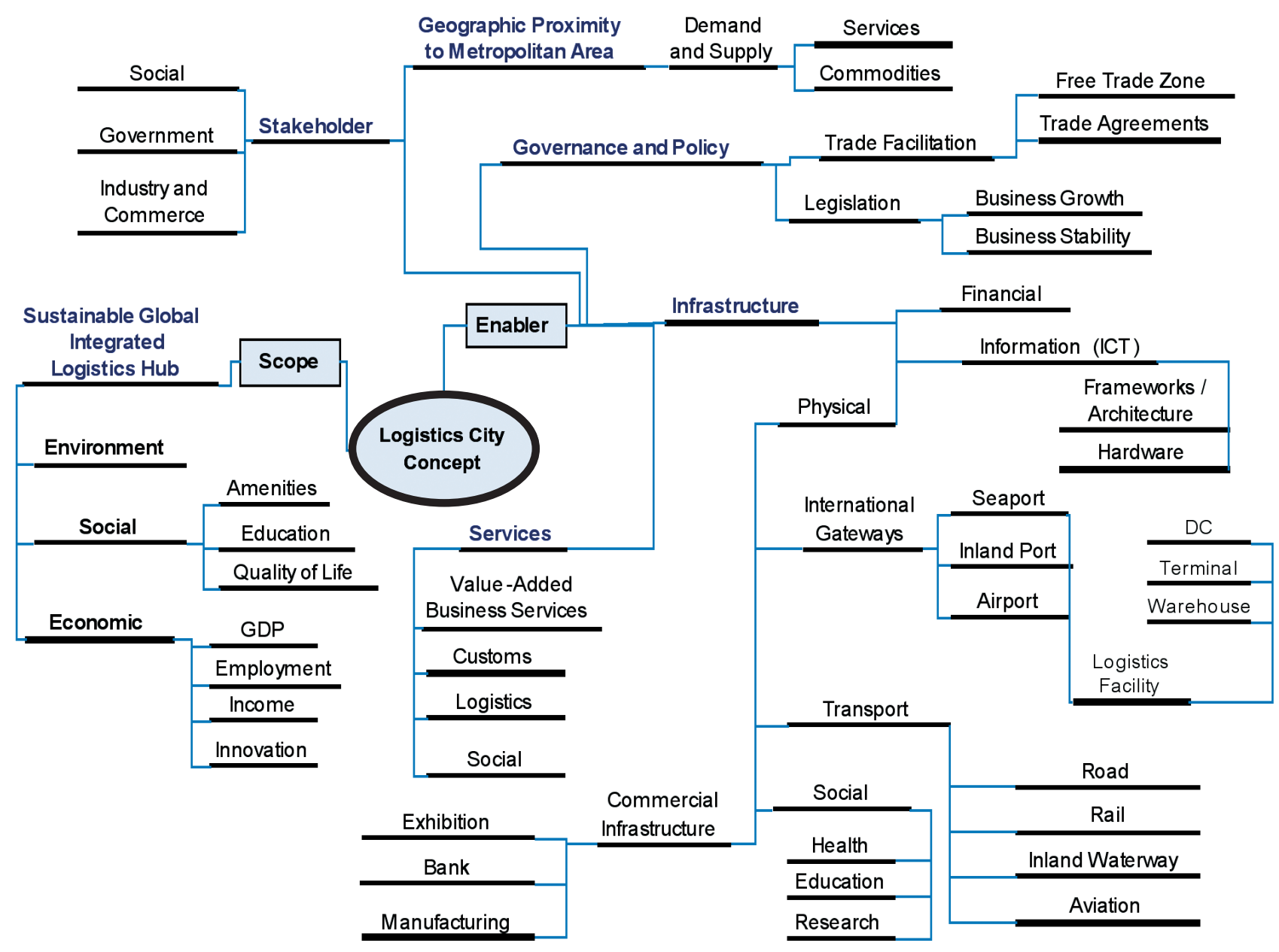

Figure 2: Conceptual map of the logistics city

In order to achieve a sustainable global integrated logistics hub, there must be a strong foundation, which is referred to in the conceptual map as enablers. These enablers have been identified as important determinants in the development of a logistics city, and the map can be extended to include others in the future.

In the model, physical, financial and information technology infrastructure play an important role in the logistics city concept. International gateways, such as seaports, airports and inland ports including their logistics facilities, are crucial to participation in the global and regional transport and distribution arena. It is clear that each logistics city and their associated gateways are unique. Two main types of logistics cities emerged that are naturally linked to their associated gateways. First there is an origin/destination city that includes so-called "export platforms" and/or "import platforms". Secondly there is the transit-type logistics city environment, which represents the hub function as it main driver. It must be noted that commonly the two types coexist; however, one of these will represent the main function of the logistics city and its associated gateways. The gateways have an important role within the logistics city; however the quality of the connectivity between these gateways, the commercial infrastructure and social infrastructure, is the major aspect. This connectivity 
can be provided by transport infrastructure, such as road and rail, or by information and communication infrastructure. The increasing cost and complexity of modern systems have meant that even the huge budgets available to governments are no longer capable of meeting the increasing pressure for upgrading and extending existing systems. As a result, it appeared that the capital needed for future infrastructure projects will not only be provided by public means. Private participation in the infrastructure investments have been discussed widely, particularly in the form of private public partnerships. In this respect the freight-user paid system has been introduced such as the German "Maut" system which was implemented in 2005. For the all motorways (Autobahn) and also some of the high frequency freight-used federal highways a toll for freight vehicles above 12 tonnes, which is based on the driven distance, number of axles and the emission category, is now mandatory.

However, transport infrastructural excellence on its own does not mean efficient connectivity, and, further, while physical transport infrastructure is seen as a necessity towards connectivity it is insufficient alone to be considered as contributing to a logistics city. The physical flow has to be complemented by information flow provided by appropriate information and communication infrastructure. As mentioned earlier, Singapore is developing a tradeintegrated information platform (one-stop platform) that will bring together the different systems to enable a seamless information transfer, supporting the already high quality existing physical infrastructure (Toh et al., 2008).

To ensure innovation in the logistics sector, which is a recognised driver for economic growth, universities and research centres focusing on logistics as part of the social infrastructure are integrated in the logistics city concept. These will ensure a specialised skilled workforce, which enables execution of the holistic concept.

Because of its size and complexity, a logistics city consists of many different stakeholders, each having different aims. Therefore it is crucial to coordinate the efforts of different stakeholders to promote and develop the logistics city concept. Lack of clear coordination will produce duplicated actions or opposing activities that will have overall negative affects. This might be seen, for example, in the efficient development of physical and virtual connectivity. Different government departments each focus on individual policies, for example road policies, rail policies, land allocation policies, and taxation policies, and these policies do not necessarily align towards the wider benefit of the logistics city. Purely investing in road transport infrastructure if congestion occurs, and not working on aligned information systems to provide better coordination and utilisation of the road system, or taking the rail policies into consideration, does not lead to a sustainable future for the logistics city. The same issues arise for industry in different areas. To mitigate this effect, Singapore has established a so-called "champion agency" to bridge all relevant private and 
public stakeholders in the area of transport and logistics. Its primary work is to promote, coordinate and develop the logistics industry in Singapore. Identifying developmental needs of private industry, working with governmental departments and agencies to remove unnecessary impediments, and aligning regulations as well as promotion are areas of responsibility for the champion agency.

The governance and policy of the logistics city concept is therefore strongly related to the needs of individual stakeholders. Legislation should be aligned to ease the physical conditions and information flow that will allow planned business growth. Additionally it is important that governance and policy systems provide stability in order that the business environment will prosper. Since one of the functions of the logistics city concept is a physical trade hub, trade facilitation should be enhanced. The logistics city of Dubai has developed a "free trade zone pathway" connecting the free zone of Dubai logistics city and the adjacent free zone of the Jebel Ali seaport as a single customs bond area.

What appeared was that the main activities of those logistics services in a logistics city are all related to adding value to goods by facilitating connectivity to and from distant markets. This common relationship of shared responsibility for connectivity translates, in a physical sense, to a gateway function. Thus, with respect to the logistics industry sectors, it is clear that these lower value-adding activities such as terminal operation, transportation and simple storage are perceived as being essential activities within a logistics city. These lower value-adding activities depend on the kind of trade gateway involved. This leads inevitably to the conclusion that the quality of these basic gateway activities is decisive for the development of a logistics city and, in the long run, its particular character and competitive strength. The decisive factors in the definition of a specific logistics city are grounded in the presence of critical mass of higher logistics value-adding activities that are commonly linked to the main gateway function. Therefore without any higher value-added services such as light assembly, customising, or packaging which are commonly executed in warehouses and without a well-developed and designed supply chain management system, a certain area should not be designated as a logistics city.

The geographical proximity of the logistics city to the intended markets is an important factor. In most existing logistics cities, historically their trade gateways and other related functions are located in densely populated areas that naturally inherit the two market segments of logistics activities, which are manufacturing and retail/wholesale as a demand and supply function. It should be appreciated that the importance of proximity to the markets is not a constant factor since different goods will have a different quantitative definition of "geographical proximity" depending on their special needs and properties. Developing an optimum market for a logistics city is an essential consideration. Apart from the manufacturing and wholesale/retail dichotomy and its possible commodities, there 
are more complex issues related to market size and quality that need to be balanced. In addition, there are immediate and important ramifications for other enablers and support services that need to be considered.

\section{CONCLUDING DISCUSSIONS}

The phenomenon of a logistics city is a concept that is almost becoming a contemporary truism, albeit with a limited systematic knowledge base in terms of academic literature. The growing importance of this concept however, makes it imperative that a comprehensive knowledge base be developed to facilitate well-structured analyses of the economic, social and environmental elements of future logistics cities. To provide these elaborate analyses, the answer to a number of key questions are seen as a necessity for further clarification, since the summarised knowledge base and developed conceptual map of the logistics city concept is still very limited. Possible subsequent questions are shown here in their logical order:

- What are the common enablers of a logistics city, and what are their properties?

- What are the external environmental influences, such as geography or politics, on the enablers of a logistics city?

- What are the main distinguishing enablers, and their properties, between a logistics city and other existing logistics-type structures such as intermodal terminals and seaports?

- What are the unique value propositions that logistics cities might contribute to the economic development of the region that it serves?

- What are possible social and environmental impacts on the region?

The proposed further research will focus on narrowing the knowledge gap by establishing a systematic logistics city framework. The objective of this framework is to allow the identification of design patterns in logistics cities and to describe these component parts in a formal and unambiguous way to enable structured analyses of possible relationships and impacts within the proposed development.

The notion of a logistics city is an emerging concept, and is being developed in response to specific contexts, experiences and economic needs of practitioners in the area. This subjectively constructed nature of the concept means that a constructivist approach is appropriate as the underpinning epistemological position for the upcoming investigation. In this respect, Fenner et al. (2005) state that the complexity of issues facing industry in the twenty-first century indicates the necessity to include constructivist epistemology to a greater extent into research related to economic, social and environmental issues. The complexity of the logistics city concept that is evident in the simplistic conceptual map, additionally favours the constructivist approach to investigation of contributing factors. A constructivist perspective emphasises that the source of knowledge lies with the actors that 
are most intimately involved with the concept under review, and the theoretical framework and methodology chosen for the investigation must be consistent with this perspective. The theoretical approach of Interpretivism, especially symbolic interaction, has been chosen to inform this investigation because of the highly symbolic nature of the concept of a logistics city which is consistent with a constructivist epistemology. The method of data collection for the upcoming research will be in-depth interviews based on a purposeful sampling approach. The driving element for the analyses will be the constant comparative method, meaning there will be constant comparison between different data sets during the analysis.

The outcomes of this investigation will be compiled into a knowledge base to further build a substantive theoretical framework. This will establish a comprehensive framework on which further possible qualitative and quantitative work can be based. Such a theoretical framework will enable accurate communication between interested parties and provide a systems approach to the engineering of logistics cities and its components. This will be important in terms of concept specifications and legal restrictions, together with the relationship between enablers, external influences and possible impacts. The beneficiaries of this work will be public authorities, property developers and industry who will be involved in making decisions for logistics infrastructure, services and social elements. 


\section{REFERENCES}

Abrahamsson, M., Aldin, N. and Stahre, F. 2003. Logistics platforms for improved strategic flexibility. International Journal of Logistics: Research and Applications. 6 (3), 85-106.

Aifandopoulou, G., Giannopoulous, G. and Haralampous, G. 2006. Development of Intermodal Freight Terminals: A methodology for building optimal networks of terminals and its application in South Eastern Europe. [CD-ROM]. Washington DC. Transportation Research Board. 01020180.

Asheim, B. and Coenen, L. 2006. Contextualising Regional Innovation Systems in a Globalising Learning Economy on Knowledge Bases and Institutional Frameworks. Journal for Technology Transfer. 31 (1), 163-173.

Asheim, B., Cooke, P. and Martin, R. 2006. The rise of the cluster concept in regional analysis and policy. In: Asheim, B., Cooke, P. and Martin, R. (eds.) Cluster and Regional development - Critical Reflections and Explorations. London: Routledge, Taylor and Francis Group. 1-28.

Asheim, B. and Gertler, M. 2005. The Geography of Innovation: Regional Innovation Systems. In: Fagerberg, J., Mowery, D. and Nelson, R. (eds.) The Oxford Handbook of Innovation. Oxford: Oxford University Press. 291-317.

Ballis, A. 2006. Freight villages: Warehouse design and rail link aspects. [CD-ROM]. Washington DC. Transportation Research Board. 01037957.

Becattini, G. 1990. The Marshallian Industrial Districts as a socio-economic notion. In: Pyke, F., Becattini, G. and Sengenberger, W. (eds.) Industrial Districts and Local Economic Regeneration. Geneva: International Institute for Labour Studies. 37-51.

Bontekoning, Y. M., Macharis, C. and Trip, J.J. 2004. Is a new applied transportation research field emerging? A review of intermodal rail-truck freight transport literature. Transportation Research Part A: Policy and Practise. 38 (1), 1-34.

Breitzmann, K.H. and Wenske, Ch. 2003. Planning of Logistics Centres. Gdansk: Final Report NeLoC Project.

Cambridge Systematics Inc. 2004. NYMTC Regional Freight Plan - An Element of the Regional Transportation Plan. New York: Report for the New York Metropolitan Transport Council. 
China Economic Review. 2007. Shenzhen's new center of gravity [online]. Available from: http://www.chinaeconomicreview.com/cer/2007_06/Shenzhen\%E2\%80\%99s_new_center_ of_gravity.html (accessed 19 August 2008).

ESCAP. 2005. Free Trade Zone and Port Hinterland Development. New York: United Nations.

Europlatforms EEIG. 2004. Logistics Centres - Direction for Use. Bologna: Report by the Presidency \& Executive Office of Europlatforms EEIG.

Fenner, R.A., Ainger, C.M., Cruickshank, H.J. and Guthrie, P.M. 2005. Embedding sustainable development at Cambridge University Engineering Department. International Journal of Sustainability in Higher Education. 6 (3), 229-241.

Hong Kong Trade Development Council. 2004. Breaking into Shenzhen Logistics Market under CEPA[online]. Available from: http://info.hktdc.com/alert/cba-e0405p1.htm (accessed 19 August 2008).

IBI Group. 2006. Inland Container Terminal Analysis. Vancouver: Final Report for the Government of British Columbia/Canada.

ICT Working Group. 2002. Singapore 2012: The Living Digital Hub - where IT Works: Singapore: Report by the Economic Review Committee ICT Working Group.

ILSCM. 2007a. A Case for a National Logistics City: Positioning the west for the Future. Melbourne. Technical Report, Institute for Logistics and Supply Chain Management, Victoria University.

ILSCM. 2007b. East-West Link needs Assessment. Melbourne. Technical Report, Institute for Logistics and Supply Chain Management, Victoria University.

ILSCM. 2007c. Positioning the West for the Future. Melbourne. Technical Report, Institute for Logistics and Supply Chain Management, Victoria University.

Jun, L. 2004. Global Logistics giants praised Shenzhen Logistics [online]. Available from: http://www.west-logistics.com/en/news_info.asp?newsid=135 (accessed 19 August 2008).

Leach, P. T. 2006. China plans massive logistics city. Pacific Shipper. 83 (9), 118.

Leitner, S.J. and Harrison, R. 2001. The identification and Classification of Inland Ports. Austin: Technical Report, Centre for Transportation Research, University of Texas. 
Lingang Group. 2006. China's New Logistics City. Shanghai: Presentation by Harmsen, L.H., Guang, Y. and Pick, S.

Martin, R.L. and Sunley, P. 2003. Deconstructing clusters: Chaotic Concept or Policy Panacea? Journal of Economic Geography. 3, 5-35.

McCalla, R. Slack, B. and Comtois, C. 2001. Intermodal Freight Terminals: Locality and Industrial Linkages. Canadian Geographer. 45, 404-413.

MEED. 2006. Four sign up for Logistics City. Middle East Economic Digest. 50 (38), 26.

Meidute, I. 2005. Comparative Analysis of the Definitions of Logistics Centres. Transport. 20 (3), 106-110.

Morgan, K. 2004. The exaggerated death of geography: learning, proximity and territorial innovation systems. Journal of Economic Geography. 4. 3-22.

MTI-WGL. 2002. Developing Singapore into a Global Integrated Logistics Hub. Singapore: Report of the Working Group on Logistics.

Paniccia, I. 2002. Industrial Districts: Evolution and Competitiveness in Italian Firms. Cheltenham: Edward Elgar Publishing Ltd.

Porter, M. 1998. On Competition. Boston: Harvard Business School Press.

Porter, M. 1990. The Competitive Advantage of Nations. London: The MacMillan Press Ltd.

Proffitt, M. 2006. Dubai World Central: Delivering State-of-the-Art Infrastructure and Logistics Services. Dubai, 2nd Trans Middle East 2006 Dubai Exhibition and Conference.

Reich, R.B. 2001. The Future of Success: Work and Life in the New Economy. London: Random House.

Scott, A. 1988. New Industrial Spaces. London: Pion Limited.

Shenzhen Government Online. 2007. Economy: Modern Logistics [online]. Available from: http://english.sz.gov.cn/economy/200708/t20070824_230021.htm (accessed 19 August 2008). 
Sirikijpanichkul, A. and Ferreira, F. 2005. Multi-Objective Evaluation of Intermodal Freight Terminal Location Decisions. 27th Conference of Australian Institute of Transport Research (CAITR). Brisbane: Queensland University of Technology.

Tierney, S. 2004. Welcome to logistics city. Supply Chain Europe. 13 (2), 25-27.

Toh, K.T.K., Sengpiehl, C., Oakden, R., Nagel, P. and Shi, P. 2008. The National Logistics City Business and Information Systems Architecture. In: Third International Conference on Innovative Computing, Information and Control. Proceedings of ICICIC 2008 - 2214, Dalian June 2008: Conference Publishing Services.

Tsamboulas, D.A. 2005. Policies Implementation for developing Freight Villages in Greece. Athens: Presentation of the Integration of Cargo Transport Modes \& Nodes in CADSES Area Project (IMONODE).

Tsamboulas, D.A., Dimitropoulos, I. 1999. Appraisal of investments in European nodal centres for goods - freight villages: A comparative analysis. Transportation. 26 (4), 381-398.

Turner, R. 2006. Dubai vies to become logistics gateway. Shipping Digest. 83 (4324), 92-94.

Van der Lugt, L.M. and De Langen, P.W. 2005. The changing role of ports as locations for logistics activities. Journal of International Logistics and Trade. 3 (2), 59-72.

Walter, C.K., Poist, R.F. 2003. Desired Attributes of an Inland Port: Shippers vs. Carrier Perspective. Transportation Journal. 42 (5), 42-55. 